\title{
Gestión moral y gestión legal en la administración de justicia de menores en Argentina
}

\section{Moral and legal management of juvenile justice administration in Argentina}

\author{
SILVIA GUEMUREMAN \\ Doctora en Ciencias Sociales- Universidad de Buenos Aires/Argentina. Investigadora del CONICET \\ en el Instituto de Investigaciones Gino Germani-Universidad de Buenos Aires. \\ silviaguemureman@gmail.com
}

Para citar este artículo

Guemureman, S (2014) Gestión moral y gestión legal en la administración de justicia de menores en Argentina. Justicia Juris, 10(2), 44-58

Recibido: Julio 24 de 2014

Aceptado: Septiembre 25 de 2014

\section{RESUMEN}

El presente artículo se inscribe en la investigación realizada en el marco de la tesis doctoral titulada "La Cartografía moral de las prácticas judiciales de los Tribunales de menores en la Ciudad de Buenos Aires" que se propuso, entre otros objetivos comparar las sentencias condenatorias, absolutorias y sobreseimientos dictados por Tribunales Orales de menores con asiento en la Ciudad de Buenos Aires con el propósito de establecer los núcleos semánticos que justifican la aplicación o no de castigo al momento del dictado de la segunda sentencia. Así, se relevaron los Libros de Segundas Sentencias o Sentencias del $4^{o}$ de uno de los Tribunales Orales de Menores durante todo un año (2002), y durante los primeros semestres de los siguientes (2003 y 2004). Se constituyó un corpus de 286 sentencias y de 295 jóvenes imputados. El análisis se complementó con entrevistas realizadas a jueces de menores. Los jueces expresaron sus concepciones y valoraciones sobre los desenlaces posibles: exención de aplicación de la pena, perdón judicial o absolución, condena, y condena con reducción. Se procesó la información en una base de datos, y se complementó el estudio con entrevistas a los nueve camaristas que integraban los tres tribunales orales de menores. En total se realizaron 16 entrevistas, siete fueron a jueces de primaria instancia. Cada juez fue identificado con una referencia numérica.

Palabras clave: administración de justicia - justicia de menores - sentencias judiciales - "perdón judicial"- penas -

\begin{abstract}
This article is part of the research conducted as part of the doctoral thesis entitled "The moral Mapping judicial practices of juvenile courts in the City of Buenos Aires" This was proposed, inter alia comparing convictions, acquittals Oral and dismissals handed down by lower courts based in the City of Buenos Aires. The purpose of this article is to establish the semantic core that justify not applying or punishment at the time of issuance of the second sentence. Thus the Second Book of Sentences or Sentences of $4^{\text {th }}$, one of the Oral Juvenile Court for a year (2002) were surveyed, and during the first semester of the following ( 2003 and 2004). A corpus of 286 sentences and 295 youth accused was formed. The analysis was complemented by interviews with juvenile judges. The judges expressed their views and assessments on the possible outcomes: exemption from penalty, judicial pardon or acquittal, conviction, and sentencing to reduction. Information in a database was processed, and the study was supplemented by interviews with nine house cleaners who made up the three oral juvenile courts. In total 16 interviews were conducted by seven judges, who were the primary instance. Others they were discarded for this article. Every judge was identified with a numeral.

Keywords: Administration of Justice - Juvenile Justice - judgments - "judicial pardon" - -identified sentences with a balloon.
\end{abstract}




\section{Introducción}

En este artículo se aborda el dictado de sentencias por parte de los jueces de menores. En la Argentina, y según el ordenamiento legal, las personas menores de edad en conflicto con la ley son acreedoras de dos sentencias: una primera sentencia en la que se valoran "hecho y prueba", y concluye, conforme a la evidencia obtenida en la declaración de responsabilidad penal, sobreseimiento o absolución del autor o los coautores de los hechos imputados. Para aquellos a quienes se les ha dictado una declaración de responsabilidad penal luego de un período de tratamiento tutelar, debe dictársele una segunda sentencia. Esta sentencia podrá eximir a los imputados de la aplicación de pena, ("perdón judicial") o estipular una condena plena o reducida.

\section{Algo sobre la ley. Régimen penal de la minoridad (ley 22.278/80)}

El proceso penal de las personas menores de 18 años está regido por el Régimen penal de la minoridad, en adelante, RPM, ley 22.278/80 (modificada por la 22.803/83) que data de la última dictadura militar, y ha sido desde su sanción un decreto controvertido, ya que estipula como modo de resolución de las causas, una potestad infinita por parte del juez, quien tiene una facultad omnímoda para disponer de los menores infractores a la ley, sean imputables o no, según la evaluación que haga de la situación personal de cada uno (artículo $\left.1^{\underline{9}}\right)^{1}$. Tan amplia la discrecionalidad de los jueces en su ejercicio, que aun siendo un hecho nimio el que dio origen a la intervención penal, puede dictaminar medidas restrictivas, como la privación de la libertad y el alojamiento en alguna institución específica de tratamiento, y más aún, extender esas medidas hasta tanto la persona en cuestión alcance la mayoría de edad. Esta facultad omnímoda ha sido duramente criticada desde distintas posiciones doctrinarias, y la ley en su conjunto severamente cuestionada (Beloff, 2001 y García Méndez-Beloff, 1998).

No obstante las críticas y embates, el RPM ha resistido múltiples intentos de ser modificado a través de diversos proyectos de ley que vienen propiciando ora la baja de edad de imputabilidad, ora la instauración de un régimen de responsabilización penal juvenil. ${ }^{2}$

La ley 22.278 estipula que:

Artículo 2ํ․ Es punible el menor de dieciséis a dieciocho años de edad que incurriere en delito que no fuera de los enunciados en el artículo $1^{\circ}$ (de acción privada o reprimidos con pena privativa de la liber- tad que no exceda de dos años, con multa o con inhabilitación).

En esos casos la autoridad judicial lo someterá al respectivo proceso y deberá disponerlo provisionalmente durante su tramitación a fin de posibilitar la aplicación de las facultades conferidas por el artículo $4^{\mathrm{o}}$. (...)

\subsection{A propósito del artículo $4^{\circ}$}

Este es el articulo el que legisla sobre la sanción efectiva a imponer a las personas menores de edad autoras o presuntas autoras de delitos sometidas a proceso judicial. Este artículo estipula que:

Artículo $4^{\circ}$. La imposición de pena respecto del menor a que se refiere el artículo $2^{\circ}$ estará supeditada a los siguientes requisitos:

$\left.1^{\circ}\right)$ Que previamente haya sido declarada su responsabilidad penal y la civil si correspondiere, conforme a las normas procesales.

$\left.2^{\circ}\right)$ Que haya cumplido dieciocho años de edad.

$3^{o}$ ) Que haya sido sometido a un período de tratamiento tutelar no inferior a un año, prorrogable en caso necesario hasta la mayoría de edad.

Una vez cumplidos estos requisitos, si las modalidades del hecho, los antecedentes del menor, el resultado del tratamien to tutelar y la impresión directa recogida por el juez hicieren necesario aplicarle una sanción, así lo resolverá, pudiendo reducirla en la forma prevista para la tentativa.

Contrariamente, si fuese innecesario aplicarle sanción, lo absolverá, en cuyo caso podrá prescindir del requisito del inciso $2^{\circ}$.

La comprensión de este artículo es fundamental para conocer como se castiga a los jóvenes en Argentina. Tal como puede apreciarse, la efectiva imposición de una pena a un adolescente autor de un delito, solo es factible de ser aplicada solo si el joven ha cumplido ya los 18 años, si además estuvo sometido por un período de al menos un año a un tratamiento tutelar, y si previo a esto se le había declarado la responsabilidad penal, es decir, si el tribunal ${ }^{3}$ había evaluado técnicamente que el adolescente había sido efectivamente al autor o coautor del delito de referencia. 
La declaración de responsabilidad penal de la primera sentencia no supone de por sí el anticipo de la imposición de una pena en la segunda, luego de que transcurra el año de tratamiento tutelar previsto en inciso $3^{\circ}$. La declaración de responsabilidad penal constituye, al decir de los jueces, un "juicio exclusivamente técnico"(GuemuremanDaroqui 2001), de allí que para su dictado no sean tenidos en cuenta ninguno de los informes obrantes en el expediente tutelar en el cual se sigue la evolución del menor.

Luego de haber trascurrido un año de tratamiento tutelar, aún cuando el lapso de tiempo desde el dictado de la declaración de responsabilidad penal fuera menor, el tribunal se halla en condiciones de resolver definitivamente la causa. A tal efecto, tomará en consideración -tal como estipula el artículo $4^{\circ}$ - los resultados del tratamiento tutelar, es decir, los informes confeccionados por los delegados tutelares encargados del seguimiento del adolescente en cuestión y/o los informes remitidos por las instituciones a los que dicho adolescente haya sido derivado, y/o los informes de los operadores de libertad asistida si ese fuera el caso.

En cada uno de los informes se evalúa la situación presente del adolescente/joven a la luz de parámetros bien definidos: situación laboral, educacional, familiar, y relativa al comportamiento respecto a la legalidad, esto es si ha vuelto a incurrir en acciones reprochables conforme al código penal o se ha mantenido al margen.

\subsection{La sentencia del artículo $4^{00}{ }^{0}:$ ¿Qué es y qué implica?}

Esta sentencia definitiva o segunda sentencia, es también llamada "sentencia del $4^{0 \prime \prime}$, o simplemente, "cuarto" ${ }^{4}$-en referencia al artículo de la ley 22.278 que la regula. A éste artículo también se lo conoce como "perdón judicial".

Esta sentencia definitiva se nutre para su dictado ya no de las vicisitudes del hecho o conducta que ameritó el reproche judicial, sino a través de la logística del expediente tutelar, sitio en que constan almacenados y puntillosamente registrados los pasos dados por el adolescente en cuestión desde que fuera dispuesto tutelarmente ${ }^{5}$. Esta sentencia consagra el predominio de la "moral" por sobre el reproche jurídico (Guemureman, 2011, p.368).

En muchísimos casos, dado el tiempo transcurrido entre la apertura de la causa y el dictado de la segunda sentencia, el material reunido en el expediente tutelar es sumamente heterogéneo porque da cuenta de distintas fases combinadas de tratamientos diversos, y así, alternan informes institucionales, -a veces de varias instituciones- con informes de operadores de libertad asistida, con informes elaborados por los propios delegados tutelares de los juzgados, comparendos de los propios jóvenes que solicitaron eventualmente audiencias en el tribunal, testimonios de sus familiares, y vistas y resoluciones de la Defensora Pública asignada.

Al momento de pronunciar la segunda sentencia, se toman en consideración los resultados del tratamiento tutelar a los que se les asigna una carga valorativa que lo califican como positivo o negativo. En la valoración de los procesos de los jóvenes hay un margen de discrecionalidad que es irrefutable. “(...) Porque no hay regulación legal, y eso nos dificulta bastante. La única regulación legal que tenemos es, ¿le vamos a imponer una sanción o no? ¿O se la vamos a reducir"? (J13) Y dentro de ese acotado menú de opciones, los magistrados ponen de manifiesto la ausencia de estándares comunes: “(...) no hay un criterio firme, la 22.278 tiene dos renglones... no hay un criterio firme de cuando hay que absolver y de cuando hay que condenar. Esto forma parte de las reglas no escritas". Dependiendo su criterio y estimación sobre los "favorables" o "desfavorables" resultados del tratamiento tutelar, pueden absolver, reducir pena, o imponer la pena prevista de acuerdo al delito imputado. La pretensión fiscal en estos casos también acompaña esa discrecionalidad, toda vez que no se solicita condena en abstracto, solo atendiendo a las escalas previstas en código penal, sino que en la instancia de la segunda sentencia, la pretensión fiscal queda supeditada a la evaluación del tratamiento tutelar, y por ende, desdibujada.

\subsection{El beneficio absolutorio del cuarto: ¿absolución, "perdón judicial", exención de aplicación de pena?}

Puesto que hablamos de perdón, lo que hace al «te perdono» a veces insoportable $u$ odioso, hasta obsceno, es la afirmación de soberanía. Esta se dirige a menudo de arriba abajo, confirma su propia libertad o se arroga el poder de perdonar, ya sea como víctima o en nombre de la víctima. (...) la víctima sería entonces víctima, además de verse despojada de la posibilidad mínima, elemental, de considerar virtualmente, perdonar lo imperdonable (...) Cada vez que el perdón es efectivamente ejercido, parece suponer algún poder soberano. Puede ser el poder soberano de algún alma noble y fuerte, pero también de un poder del estado que dispone de una legitimidad incuestionada, de la potencia necesaria para organizar un proceso, un juicio aplicable, $\mathrm{o}$ eventualmente, la absolución, la amnistía o el perdón" (Jacques Derrida, 2003.Págs.7-39)

Tal como se explicó ut supra, la declaración de responsabilidad penal puede traducirse en una sentencia absolutoria, en realidad "beneficio absolutorio" previsto por la 
ley minoril en su artículo $4^{\circ}$ que faculta al juez para dictar absolución en los casos en que no resulte necesario aplicar una sanción a expensas de un tratamiento tutelar que arroje buenos resultados . Esta "beneficio absolutorio" plantea una discusión jurídica que no está saldada entre los actores que integran los tribunales, ya que en estos casos, la absolución no es sinónimo de falta de responsabilidad en el hecho investigado -recordemos que la declaración de responsabilidad penal ya fue dictada y acreditó la participación del adolescente- sino que equivale a la "eximición de la aplicación de pena", y en este sentido su naturaleza es distinta de la sentencia absolutoria tal como se entiende comúnmente. Uno de los jueces, relata que cuando empezó a estudiar el tema, se dio cuenta que excepto Raúl Horacio Viñas $(1984)^{7}$, ninguno de los juristas se había planteado "dónde entraba la absolución del cuarto" y el tema estaba ausente de la dogmática penal, y llega a la conclusión que "la principal naturaleza jurídica de esta absolución, y está lo que se llaman las «condiciones objetivas de punibilidad o las excusas absolutorias» también (J6).

Las opiniones se dividen entre aquellos que afirman que se trata de un derecho, y aquellos que le otorgan el carácter de "perdón judicial". Una posición de una claridad encomiable acerca de la tesitura del "perdón judicial" es la que han expresado los Fiscales en reiteradas ocasiones: "Así también y en lo que atañe al régimen de menores, es menester que se considere mediante reforma legislativa, la posibilidad de trocar en el artículo $4^{\circ}$ de la ley 22.278. El término "absolución" por el de "perdón judicial de la pena", lo que es en esencia su real naturaleza jurídica, evitando así confusiones al respecto, toda vez que el término absolución debe adjudicarse a los casos en que por falta de prueba o por dudas no es posible atribuir un hecho punible aun encausado, en tanto que la sentencia proveniente del artículo $4^{\circ}$ de la ley 22.278 se refiere al caso en el cual, luego de constatarse que el encausado es el autor ó coautor del hecho, el buen resultado del tratamiento tutelar y la proyección de un futuro favorable tornan innecesaria la aplicación de pena" ${ }^{8}$.

Un testimonio partidario de la absolución como derecho, es lo expresado por este juez: " (...) la absolución es un derecho, y no una gracia del estado, por la sencilla razón de que si el chico hace todo bien, y lo condenás, esa condena es arbitraria por lo que la absolución es un derecho". (J6). El debate adquiere ribetes más jurídicos. Es ilustrativo el planteo de un juez que afirma que aplicar una figura indistinta es injusta para aquel que es inocente; "ese, se pregunta un juez- porque va a tener una absolución por perdón si él no fue?".

Todas estas posiciones desfilan en las sentencias de los tribunales orales de menores, por eso, en este artículo se analizará un corpus de segundas sentencias dictadas por uno de los tribunales Orales de Menores de la Ciudad de Buenos Aires entre los años 2002-2003 y 2004 y se triangulará con extractos de entrevistas en los que los jueces hablaron sobre los que hacen en su labor de administración de justicia. El libro de Sentencias es un bibliorato en el que están archivadas las sentencias. En el caso de las personas menores de edad, hay un Libro de Primeras Sentencias, o las "declaraciones de responsabilidad penal", y un libro de Segundas Sentencias, o las "Sentencias del 4"

\section{Metodología: criterios de relevamiento de la muestra de sentencias y entrevistas.}

El relevamiento se hizo en forma artesanal, realizando la previsión de un análisis posterior de tipo cuantitativo y uno de tipo cualitativo, se relevaron los siguientes campos:

Número de sentencia, fecha, datos del imputado ${ }^{10}$-cuando los hubiera-, Fiscal, Defensor y Asesor interviniente, delito atribuido, fecha/s de la declaración/es de responsabilidad penal, existencia de otras causas, en cuyo caso se tomó la referencia del juzgado y la información disponible sobre la causas referenciadas, dictamen sobre la aplicación del tratamiento tutelar, carácter de la sentencias, (absolutoria o condenatoria), otras resoluciones tomadas (cese de tutela, ordenamiento de libertad, cumplimiento de condiciones, etc.); jurisprudencia citada, disidencias planteadas - si las hubiera motivos aludidos y situación ambulatoria de los jóvenes al momento de serles dictada la sentencia (institucionalización, libertad, libertad condicional, libertad asistida). A los efectos de un análisis de tipo cualitativo, se tomo registro de los considerandos que hacen los magistrados sobre el resultado del tratamiento tutelar en los cuales aparecen las valoraciones personales de los magistrados, y su ideología.

Asimismo esta dimensión ideológica y de cosmovisión sobre la legitimidad del tratamiento tutelar y el dictado de sentencias absolutorias y condenatorias se profundizó a través de entrevistas a los magistrados que se desempeñaban en los TOM.

\section{Los resultados: Síntesis cuantitativa sobre el dictado de segundas sentencias}

El relevamiento realizado, arrojó que en año 2002, el TOM № 1 dictó 140 segundas sentencias, que involucraron a 144 personas que cometieron delitos siendo menores de 18 años. De estas personas, había 137 varones y 7 mujeres.

Para el año 2003, la razón de segundas sentencias dictadas se mantiene constante, ya que durante el primer semestre 
se dictaron 71 sentencias, lo que arroja una proporción similar. Estas sentencias involucraron a 72 varones y solamente 1 mujer. (73 sentencias en total).

En el año 2004, la cantidad de segundas sentencias pronunciadas no difirió en demasía, ya que el relevamiento arrojó un total de 75 sentencias para el primer semestre, que incluyeron a 78 jóvenes. Las mujeres marcaron mayor presencia, con seis casos. Los otros 72 involucrados fueron varones.

En total, la base de datos a analizar consta de 286 sentencias y de 295 jóvenes imputados, de los cuales sólo 14 fueron mujeres.

\section{1 Acerca de la declaración de responsabilidad penal}

Todos los jóvenes llegados a esta instancia tuvieron, al menos, una declaración de responsabilidad penal en su contra, e incluso no es infrecuente encontrar chicos con hasta dos y tres declaraciones de responsabilidad penal. También es frecuente que al momento del dictado de la segunda sentencia, los jóvenes tuvieran otras causas abiertas, en el mismo o en distintos tribunales, en muchos casos de otras jurisdicciones. El 40\% de los jóvenes tenían otras causas abiertas con algunas fluctuaciones. En el año 2002, el 39,19\% de los imputados al momento de la sentencia tenían otra causa abierta en otro tribunal, en muchos casos de apertura posterior a la declaración de responsabilidad penal, implicando esto que "incurrió en conductas de riesgo que debió evitar tal como prueba la existencia de otras causas", o bien "pese a la severa advertencia recibida luego de la DRP el imputado no obedeció las pautas proporcionadas por el Tribunal"11. En el año 2003 estaban en esa situación un 30,13\% de los imputados, de los cuales el 72,2 \% ya tenía sentencia firme. En el año 2004, los que tenían otras causas representaban un $52,56 \%$ del universo relevado, de los cuales mas de la mitad, el 58,53\% tenían sentencia firme. ${ }^{12}$

\subsection{Acerca de los delitos imputados}

Con relación a los delitos atribuidos, debe tenerse en cuenta que hay muchos casos que los imputados presentan más de una causa en el mismo tribunal, por ende, tuvieron más de una declaración penal. La tipificación de los delitos es compleja porque amen de los hechos típicos previstos en el código penal, están los "concursos" que suponen otras combinatorias13.

La mayor cantidad de hechos está constituida por los delitos contra la propiedad, consumados o tentativas, simples o calificados.

Entre las calificaciones, encontramos, las más usuales de robo calificado por arma, y robo calificado por haber sido cometido en poblado y en banda, luego los robos doblemente agravados, en que concurren dos agravantes, las reiterancias (referencia a la cantidad de oportunidades) y los concursos reales o ideales.

Son muy pocos los casos que aluden a delitos que no hayan sido contra la propiedad. Solamente aparecen consignados los delitos de "portación de arma de uso civil sin la debida autorización legal" en 4 oportunidades; la tenencia de arma de guerra en 3, la misma figura pero con el agravante de encubrimiento en otras 3 , y también en 1 ocasión la tenencia con el agravante de coacción agravada.

Delitos contra las personas aparecieron en cuatro ocasiones, 1 tentativa de homicidio, y lesiones agravadas en 3 causas; sólo una vez apareció el abuso sexual. El encubrimiento a secas apareció en otras dos ocasiones; hubo otros dos casos sin ninguna referencia. Sólo 20 sentencias podrían asignarse a tipos delictuales diferentes de los encuadrados en el Título VI de "Delitos contra la propiedad". Entre éstos últimos hay preeminencia de robos, aunque hay 7 casos de hurtos, tres consumados y cuatro

\begin{tabular}{|l|c|c|c|c|}
\hline \multicolumn{1}{|c|}{ Tiene condena en otra causa } & $\mathbf{2 0 0 2}$ & $\mathbf{2 0 0 3}$ & $\mathbf{2 0 0 4}$ & Total \\
\hline \multirow{2}{*}{$\begin{array}{l}\text { Sí, firme } \\
\text { Sí, en apelación }\end{array}$} & 38 & 16 & 24 & 78 \\
\cline { 2 - 5 } $\begin{array}{l}\text { No aún en trámite } \\
\text { Sí en suspenso }\end{array}$ & 3 & 1 & 0 & 4 \\
\hline Total con otra causa & 3 & 5 & 13 & 29 \\
\cline { 2 - 5 } & $\mathbf{5 5 ( 3 8 , 1 9 \% )}$ & $\mathbf{2 2} \mathbf{( 3 0 , 1 3 \% )}$ & $\mathbf{4 1} \mathbf{( 5 2 , 5 6 \% )}$ & $\mathbf{1 1 8} \mathbf{( 4 0 \% )}$ \\
\hline No tienen otra causa & $\mathbf{8 9}$ & $\mathbf{5 1}$ & $\mathbf{3 7}$ & $\mathbf{1 7 7}$ \\
\hline Total & $\mathbf{1 4 4}$ & $\mathbf{7 3}$ & $\mathbf{7 8}$ & $\mathbf{2 9 5}$ \\
\hline
\end{tabular}

Fuente: Elaboración propia en base a relevamiento de segundas sentencias en TOM №1 
en grado de tentativa14. En el caso de los robos, hubo 149 hechos consumados. Hubo 96 robos "tentados", y otros 4 casos mixtos, que concursan hechos consumados con hechos tentados. Además se registró un secuestro extorsivo.

\subsection{El Tratamiento tutelar: Dictamen y resultados}

En las sentencias del "cuarto", el apartado destinado a resumir los resultados del tratamiento tutelar, son amplios, y habilitan a que según el mejor criterio del magistrado que lleva la causa, puedan incorporarse un sinnúmero de informes y pruebas. Las segundas sentencias se resuelven por escrito y no en audiencia15. En cualquiera de los casos, es indispensable a los efectos de fundamentar la sentencia, que ésta contenga algunos tópicos esenciales, como un recorrido exhaustivo por diferentes aspectos de la vida que hacen a la evolución del adolescente o joven que viene transitando por el ámbito judicial.

Estos tópicos de análisis se condensan en mirar la evaluación del joven en modo integral: educación, trabajo, actitud conforme a las normas, consumos, amistades, responsabilidades familiares, etc. Es interesante pasar revista a los formulismos con que los jueces hacen preceder sus dictámenes16:

“Que de la lectura del expediente tutelar № 1172/1305 del registro de éste Tribunal y de los presentes actuados surge, claramente, la innecesariedad de imponer pena a XXXX en orden a los delitos en los que participó siendo menor de dieciocho años de edad";

O también,

"Que de la lectura del expediente de disposición tutelar № 1428 del registro de este Tribunal y de los presentes actuados surge, claramente, que no resulta necesario imponer pena a ZZZZ en orden al delito en el que participó siendo menor de dieciocho años de edad".

Para el caso de que sí considerara necesario imponer pena, estas son las fórmulas típicas que surgen del relevamiento de las sentencias (en escala de mayor a menor neutralidad):

"que no resulta procedente la absolución de NNNNN BBBBB prevista en el artículo $4^{0}$ de la ley 22.278";

"es claro que MMMM SSSSSS no se ha hecho acreedor a ninguno de los beneficios previstos en el art. $4^{\circ}$ de la ley 22.278";
“Que de la lectura del Expediente Tutelar № 751 del registro de este Tribunal y de los presentes actuados surge, fehacientemente que no resulta procedente la absolución de AAAA prevista en el artículo $4^{\circ}$ de la Ley 22.278 en orden al injusto que cometiera siendo menor";

Es interesante connotar que cuando se hace alusión al carácter de "beneficio" de la instancia prevista en el artículo $4^{\circ}$ de la ley 22.278 , se refiere que se ha hecho acreedor, o no se ha hecho acreedor, porque un beneficio, para distinguirlo de una gracia, es algo que debe ser merecido, es decir, "acreditado", se deben juntar créditos para alcanzarlo, en términos de Derrida, este perdón equivaldría a una acción mercantil17. Por ende, no haberse hecho acreedor de "ningún" beneficio, califica de por sí la valoración que el juez o el tribunal hacen del tratamiento tutelar.

En los casos en los cuales simplemente se menciona el artículo $4^{\circ}$ de la ley, sin matices valorativos, las referencias son a la "necesidad" o "innecesariedad" de aplicar pena, o a la procedencia o improcedencia de la absolución. El "fehacientemente" es simplemente un reforzador.

\subsection{Distribución de beneficios, y distribución de sanciones}

En orden a la distribución y frecuencia, puede decirse que los dictámenes respecto al tratamiento tutelar, son mayoritariamente, dictámenes que no consideran necesaria la aplicación de pena. Así, en todo el período, $65,77 \%$ de los dictámenes fueron absolutorios, y 32,7\% condenatorios. El restante 4,03\% correspondió a sentencias de unificación.

Una distribución por año, da cuenta que para el año 2002 hubo un 59,72 \% (86 casos) 18 en los cuales se dictaminó sobre la "innecesariedad de imponer sanción" ya que "aplicar una sanción configuraría adoptar un criterio meramente retributivo y desconocer los esfuerzos y logros que el imputado ha realizado dentro de las condiciones que le permite su medio social"; en el año $2003 \mathrm{el}$ porcentaje ascendió al 73,97\% (54 casos). En el año 2004, guarismo había descendido al $69,23 \%$ pese a mantenerse la cantidad de casos (54 casos). Respecto a la no procedencia del beneficio absolutorio, se registró en 35,41\% (51 casos) para el año 2002, un 20,55\% para el 2003 (15 casos) y un $29,49 \%$ ( 23 casos) en el 2004. Los otros casos correspondieron a sentencias de unificación, o sea que fueron sentencias que tomaron en consideración otras condenas preexistentes (7 para el año 2002 y 4 para el año 2003 y 1 para el 2004). 


\begin{tabular}{|l|c|c|c|c|}
\hline \multicolumn{1}{|c|}{ Dictamen TT } & $\mathbf{2 0 0 2}$ & $\mathbf{2 0 0 3}$ & $\mathbf{2 0 0 4}$ & Total \\
\hline Innecesariedad de aplicar sanción & $86(59.72 \%)$ & $54(73.97 \%)$ & $54(69,23 \%)$ & $\mathbf{1 9 4}(\mathbf{6 5 . 7 6} \%)$ \\
\hline No procede absolución art. 4⿳一 & $51(35.41 \%)$ & $15(20.55 \%)$ & $23(29.49 \%)$ & $\mathbf{8 9 ( 3 0 , 2 \% )}$ \\
\hline Sentencia unificación & $7(4.86 \%)$ & $4(5.48 \%)$ & $1(1.28 \%)$ & $\mathbf{1 2}(4.07 \%)$ \\
\hline Total $^{19}$ & $\mathbf{1 4 4}(\mathbf{1 0 0 .} \%)$ & $\mathbf{7 3 ( 1 0 0 \% )}$ & $\mathbf{7 8 ~ ( 1 0 0 \% )}$ & $\mathbf{2 9 5}(\mathbf{1 0 0} \%)$ \\
\hline
\end{tabular}

Fuente: Elaboración propia en base a procesamiento sentencias TOM №1

\section{4 Cuando sí, cuando no, desde los jueces: Consensos mínimos}

a. Para Absolución

J13: Si el tratamiento tutelar funcionó, no hay razones para la sanción. Esta es la lógica. Y no hay vuelta que darle.

J6: el chico que cumple con las pautas tutelares, tiene derecho a que se lo

absuelva. Si el chico tiene derecho a que se lo absuelva, quiere decir que hay un determinado momento en que la persecución del estado a ese chico por ese delito no es legítima. ¿Por qué? Porque la consecuencia jurídica de la acción ilícita que cometió se cortó. ....

b. Condena, pero ¿con o sin reducción? A favor y en contra de la reducción punitiva

J11: Entonces cuál es el criterio según mi gusto, para ver si hay que fijar, si se aplica pena atenuada o pena completa: el grado de esfuerzo que hizo esta persona dentro de sus posibilidades para haberse responsabilizado de la situación al margen de hecho (...). Esto tiene que ver con los fines de la pena en el proceso de menores que es primordialmente educativa y socio- educativa, pero sí la pena no cumple el mismo rol que en el sistema de adultos. Claramente, y eso todo el mundo te lo dice, la prevención especial es lo único que opera en el sistema de menores y la prevención general no tiene ninguna incidencia. La prevención general es negativa, lo que busca es que la gente se motive en la norma, y por ende, es disuasiva, entonces, la ley de menores sólo puede tener como fin la prevención especial. Entonces si vos lo tomás con todo este bagaje de valores yo no tengo ninguna duda de que la reducción debe ser la regla.

J12-2 es claro que la Corte sigue en la misma posición de que la reducción es obligatoria, si afirma que no se puede tratar igual que un adulto, es claro que la reducción es obligatoria. c. Lo irreductible también existe

J11: Y sólo relevo la posibilidad de condenar a pena completa cuando son esos casos en donde el hecho es muy grave, el chico no hizo nada para zafar, etc. Lo habré aplicado dos o tres veces, uno fue Miliorini20. Que fue robo con armas, mató al tipo en el negocio, se había escapado de una Comunidad terapéutica, no tenías de dónde agarrarte, al tipo de la guardia le decía "me bajé al cobani". Es como que no había nada para reducirle. Y después fue otro chico que tenemos nosotros que tenía creo que 12 causas, comportamiento pésimo en la unidad, le pegaba a los otros chicos, les afanaba a todos, un chico complicado.

\subsection{Sentencias absolutorias y sentencias condenatorias}

Los casos en que se dictaminó innecesariedad de imponer sanción, se tradujeron en sentencias absolutorias.

Una lectura cruzada de las sentencias condenatorias y los delitos atribuidos a los jóvenes requiere de otros elementos de análisis a considerar, por ejemplo, la existencia de otras causas en trámite, y la preexistencia de otras sentencias condenatorias en otros juzgados o tribunales. De otro modo, no podría explicarse que haya jóvenes que según la causa por la cual son juzgados en el TOM №1 expresen tal heterogeneidad en sus montos. Valga como ejemplo, por el delito de robo simple, hay 7 casos condenados hasta 2 años de prisión, 1 caso condenado a más de tres años, y 1 caso condenado a una pena comprendida entre los 5 y los 10 años. La misma situación ocurre con los delitos de robo cometidos en poblado y en banda. En los delitos concursados, usual y previsiblemente, las condenas son más altas.

Hubo 118 pronunciamientos efectuados sobre jóvenes que ya tenían otras causas penales, en algunos casos, 1 , en otros dos, y también casos de mas de 3 causas abiertas. Sin embargo, en 26 casos esto no impide que sean dictadas las absoluciones cuando la existencia de otras causas es un elemento de valoración preponderante para los magistrados21. De éstos 26 casos, 15 aún tenían las causas en trámite, es decir, hay presunción de inocencia. 
Se detectaron otros 7 casos de condenas en firme. O sea, es esperable la sanción, sin embargo, puede no haber sanción. Los jueces pueden preferir no22 castigar23. Estas reflexiones proceden de la formula bartlebiana "preferiría no hacerlo" de Baterbly, el escribiente, de H. Melville que tanto ha dado que hablar. Dice Gilles Deleuze en el ensayo "Bartleby o la fórmula", "lo desolador de la fórmula es que elimina tan despiadadamente lo preferible como cualquier no preferencia en particular. Amula el termino al que afecta y rechaza, pero también al otro, aquel que aparentemente conserva y se torna imposible. De hecho, convierte a ambos términos en indistintos: erige una zona de indiscernibilidad, de indeterminación, incensantemente creciente, entre las actividades no preferidas y la actividad preferible. Toda particularidad y toda referencia, quedan abolidas"

La mayoría de las absoluciones (167) se dictaron para quienes no tenían otras causas en su haber, aunque haya habido casos que aun no teniendo otras causas, igualmente fueron condenados (10), pudiendo no ser, fueron, los jueces "prefirieron no" absolver.

En más detalle, puede observarse en el cuadro que sigue:

Las otras 80 sentencias condenatorias corresponden a lo esperable: se dictaron sobre jóvenes sobre los que ya pesaban otras condenas. En 58 casos ya tenían condenas firmes.

\subsection{Disidencias: puntos de tensión y modos de resolución}

Es factible que los camaristas no arriben a las mismas conclusiones cuando se trata de evaluar el tratamiento tutelar de un joven, y más aún si de esa evaluación depende una decisión tan trascendente como la imponer o no pena. Es justamente porque la valoración del tratamiento tutelar en sus aristas morales, no solamente legales es tan subjetiva, que al momento de pronunciarse la segunda sentencia aparecen las disidencias, que expresan distintos puntos de vista y distintas ponderaciones sobre la persona del joven. En el relevamiento realizado, hubo 62 disidencias24 en total, 27 pronunciadas sobre sentencias absolutorias, $y$ 35 sobre sentencias condenatorias.

Los motivos de disidencia son más variados en las sentencias absolutorias; en las condenatorias, las disidencias se reducen a discusiones sobre la aplicación o no de la reducción punitiva, y el monto de las condenas aplicadas. A continuación se presenta el detalle de las disidencias por año:

La reducción punitiva constituye una verdadera división de aguas entre los camaristas que integran el tribunal: hay jueces que asumen la reducción punitiva como norma en las sentencias condenatorias (es casi un beneficio automático), y otros que lo supeditan a otros elementos -indicadores, por ejemplo, una gran cantidad de causas producidas con posterioridad a la DRP, hace suponer que hay "proclividad al delito", y por ende, el beneficio de la

\begin{tabular}{|c|c|c|c|c|c|c|c|c|c|}
\hline \multirow[b]{2}{*}{ Sentencia $1^{\circ}$ imputado } & & & & \multicolumn{5}{|c|}{ Tiene condena en otra causa? } & \multirow[b]{2}{*}{ Total } \\
\hline & & & & si, firme & $\begin{array}{c}\text { si, en } \\
\text { apelacion }\end{array}$ & $\begin{array}{c}\text { no, aun en } \\
\text { tramite }\end{array}$ & $\begin{array}{c}\text { sí, en } \\
\text { suspenso }\end{array}$ & $\begin{array}{c}\text { no } \\
\text { corresponde }\end{array}$ & \\
\hline \multirow[t]{3}{*}{ absolutoria } & $\begin{array}{l}\text { causa si } \\
\text { o no }\end{array}$ & 1 & $\begin{array}{l}\text { Recuento } \\
\% \text { de Tiene condena } \\
\text { en otra causa? }\end{array}$ & $\begin{array}{r}7 \\
100,0 \%\end{array}$ & & $\begin{array}{r}15 \\
100,0 \%\end{array}$ & $\begin{array}{r}3 \\
100,0 \%\end{array}$ & $\begin{array}{r}1 \\
, 6 \%\end{array}$ & $\begin{array}{r}26 \\
13,9 \%\end{array}$ \\
\hline & & 2 & $\begin{array}{l}\text { Recuento } \\
\% \text { de Tiene condena } \\
\text { en otra causa? }\end{array}$ & $\begin{array}{r}0 \\
, 0 \%\end{array}$ & & $\begin{array}{r}0 \\
, 0 \%\end{array}$ & $\begin{array}{r}0 \\
, 0 \%\end{array}$ & $\begin{array}{r}161 \\
99,4 \%\end{array}$ & $\begin{array}{r}161 \\
86,1 \%\end{array}$ \\
\hline & Total & & $\begin{array}{l}\text { Recuento } \\
\% \text { de Tiene condena } \\
\text { en otra causa? }\end{array}$ & $\begin{array}{r}7 \\
100,0 \%\end{array}$ & & $\begin{array}{r}15 \\
100,0 \%\end{array}$ & $\begin{array}{r}3 \\
100,0 \%\end{array}$ & $\begin{array}{r}162 \\
100,0 \%\end{array}$ & $\begin{array}{r}187 \\
100,0 \%\end{array}$ \\
\hline \multirow[t]{3}{*}{ condenatoria } & $\begin{array}{l}\text { causa si } \\
\text { o no }\end{array}$ & 1 & $\begin{array}{l}\text { Recuento } \\
\% \text { de Tiene condena } \\
\text { en otra causa? }\end{array}$ & $\begin{array}{r}58 \\
100,0 \%\end{array}$ & $\begin{array}{r}4 \\
100,0 \%\end{array}$ & $\begin{array}{r}13 \\
100,0 \%\end{array}$ & $\begin{array}{r}2 \\
100,0 \%\end{array}$ & $\begin{array}{r}1 \\
10,0 \%\end{array}$ & $\begin{array}{r}78 \\
89,7 \%\end{array}$ \\
\hline & & 2 & $\begin{array}{l}\text { Recuento } \\
\% \text { de Tiene condena } \\
\text { en otra causa? }\end{array}$ & $\begin{array}{r}0 \\
, 0 \%\end{array}$ & $\begin{array}{r}0 \\
, 0 \%\end{array}$ & $\begin{array}{r}0 \\
, 0 \%\end{array}$ & $\begin{array}{r}0 \\
, 0 \%\end{array}$ & $\begin{array}{r}9 \\
90,0 \%\end{array}$ & $\begin{array}{r}9 \\
10,3 \%\end{array}$ \\
\hline & Total & & $\begin{array}{l}\text { Recuento } \\
\% \text { de Tiene condena } \\
\text { en otra causa? }\end{array}$ & $\begin{array}{r}58 \\
100,0 \%\end{array}$ & $\begin{array}{r}4 \\
100,0 \%\end{array}$ & $\begin{array}{r}13 \\
100,0 \%\end{array}$ & $\begin{array}{r}2 \\
100,0 \%\end{array}$ & $\begin{array}{r}10 \\
100,0 \%\end{array}$ & $\begin{array}{r}87 \\
100,0 \%\end{array}$ \\
\hline \multirow[t]{2}{*}{ unificacion de pena } & $\begin{array}{l}\text { causa si } \\
\text { o no }\end{array}$ & 1 & $\begin{array}{l}\text { Recuento } \\
\% \text { de Tiene condena } \\
\text { en otra causa? }\end{array}$ & $\begin{array}{r}12 \\
100,0 \%\end{array}$ & & & & & $\begin{array}{r}12 \\
100,0 \%\end{array}$ \\
\hline & Total & & $\begin{array}{l}\text { Recuento } \\
\% \text { de Tiene condena } \\
\text { en otra causa? }\end{array}$ & $\begin{array}{r}12 \\
100,0 \%\end{array}$ & & & & & $\begin{array}{r}12 \\
100,0 \%\end{array}$ \\
\hline
\end{tabular}

Fuente: Elaboración propia en base a procesamiento sentencias TOM №1 


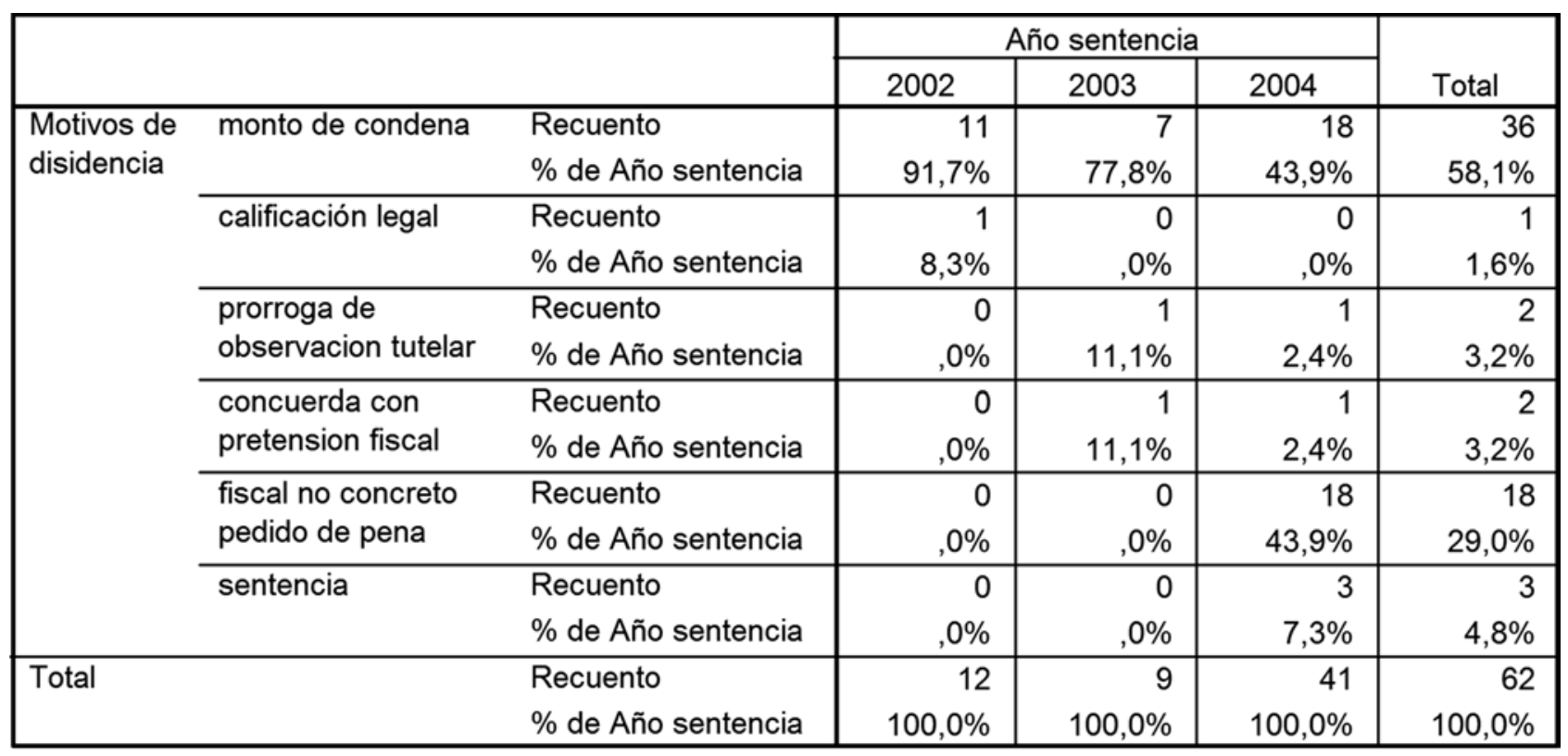

Fuente: Elaboración propia en base a procesamiento sentencias TOM №1

absolución no procede. Depende cual de los jueces funde el voto, las argumentaciones aparecerán con más o con menos fuerza. 25

De tal suerte, que por esa situación de vulnerabilidad, por las características propias de los adolescentes y por la obligación constitucional de condenar a los menores únicamente como último recurso y por el tiempo más breve posible, considero que la reducción prevista en el art. $4^{\circ}$ de la Ley 22.278 -cuando no proceda la absolución - debe ser la regla general, limitándose la condena en similares condiciones que los adultos a aquellos casos en que, por la gravedad del hecho, por la reiteración delictiva o por el pésimo comportamiento del incusado, pueda aseverarse que tampoco el joven se hizo acreedor a dicha solución"(Voto Juez C-TOM №1 - Sentencia).

Hay otra postura que llega a la misma conclusión, en términos de monto de la condena, pero no atribuye su cómputo a la regla de la reducción punitiva, sino a los artículos 40 y 41 del CP (audiencia personal):

estimo suficiente la propuesta por el Dr. J3 de seis meses de prisión en mérito a las pautas de graduación que disponen los arts. 40 y 41 del Código Penal"

Ampliación posición: (...)Respecto de su historia de vida y carencias que influyeron en su comportamiento, como ya lo sostuve en otras ocasiones, son parámetros para la graduación de las penas que alcanzan por igual a mayores y menores pero no circunstancias que por regla deban valorarse para conceder el beneficio de la reducción punitiva (Voto Juez B-TOM №1, Sentencia).

En otros tramos, aclara aun más, refuerza su posición:

Como ya lo señalara en otras oportunidades, los parámetros destacados por el preopinante para arribar a la concesión del beneficio, como lo son la historia de vida, falta de contención familiar y tendencia a involucrarse en situaciones de riesgo, son pautas que alcanzan a todos los imputados y que deben tenerse en cuenta para la graduación de la pena, pero que son ajenos a los beneficios de la ley minoril, para cuyo logro, es necesario que el menor responda de alguna manera al tratamiento tutelar. Precisamente, la vulnerabilidad que caracteriza a los menores sometidos a nuestra competencia, es la que justifica a su respecto la aplicación de una ley especial, que entre otras cosas, les concede el beneficio de la reducción punitiva, pero entiendo que el mismo no es de aplicación automática sólo por revestir el incuso tal condición, sino que debe concederse cuando el causante ha hecho algún mérito que lo justifique, que no es precisamente el caso que nos ocupa" (Voto Juez B-TOM №1, Sentencia).

La posición que entiende que la reducción punitiva debe ser la regla, y no la excepción inscribe la reducción obligatoria en la esfera de la Convención de los Derechos del Niño, y no de las pautas de mensuración de los artículos 
$40^{\circ}$ y $41^{\circ}$ del Código Penal: nuevamente, un derecho, y no un beneficio 26

J11: El punto es que yo para hacer el cuarto con la reducción tenía que evaluar el tutelar. Y la sentencia de (JUEZ A) no venía muy bien. La de (JUEZ B), sí. Lo que dice el JUEZ B a mi criterio de la reducción obligatoria es que dice que lo que yo tomo como pauta para reducir, son las pautas que el $41^{\circ}$ da en el Código Penal para fijar la pena de cualquier persona, y que por lo tanto no es cierto que la reducción sea obligatoria. Porque lo que yo tengo ante esto es, justamente, el sistema de menores, por la Convención, estas pautas del $40^{\circ}$ a $41^{\circ}$ determinan el grado de vulnerabilidad de un chico, o el grado de influenciabilidad o la influencia que había tenido sus experiencias de vida con la actuación posterior. Yo leí muchas actuaciones, estoy leyendo a Winicott ("Deprivación y delincuencia") y vos leés a Winicott y es muy claro esto. El mismo dice que esto no se tiene que traducir en perdonar, sino que tiene que traducirse en responsabilizar.

Otros temas que han sido motivo de disidencias, y no aparecen en el registro estadístico, son las disidencias que se pronuncian al interior de los expedientes tutelares, en que los jueces debaten conjuntamente las medidas a adoptar. En este terreno, en donde más que nunca se ponen en juego ideologías acerca del fin de la pena, vinculados a "defender la sociedad": allí empiezan a aparecen diferencias en cuanto a la prognosis de los jóvenes, que dibujan escenarios de peligrosidad, de resistencia a recuperación, a la realización de tratamientos, a "retomar la buena senda".

Las posiciones encontradas usualmente se resuelven por mayoría simple, de dos votos a uno, aunque difiere la composición de la mayoría, que si bien tiende a consolidarse en un tandem 2 a 1 automático, la valoración del mérito, teñida de subjetividad, es la que termina definiendo, y vuelca la balanza hacia uno u otro lado.

\section{Síntesis: Debate jurídico, y posiciones de los jueces: el imperio de la moral prevalece sobre la doctrina}

Una característica de las sentencias de los tribunales de menores es que no abrevan en complejos debates jurídicos para su fundamentación. Más vale, las sentencias siguen una estructura típica en que la evaluación del tratamiento tutelar en sus aristas más elocuentes, es material suficiente que no requiere de mayor fundamentación jurídica. Son discursos típicamente argumentativos que se respaldan en valoraciones morales más que en consideraciones legales (Guemureman, 2011, págs. 349 y ss.)
Los discursos argumentativos típicos concatenan las frases utilizando argumentos lógicos. Estos argumentos se encadenas en forma doxal, y paradojal. Según Ducrot-Carel (2002), los encadenamientos doxales están mediados en por lo tanto, y los paradojales, en sin embargo27. El relato de los expedientes tutelares de los jóvenes que los jueces realizan en la segundas sentencias reconocen esta singularidad.

Se utiliza el relato por lo tanto cuando se quiere mostrar una resolución como consecuencia lógica de las acciones objetivas de los jóvenes. Es decir, los relatos concadenados en por lo tanto, refieren a lo esperable. Este modo es utilizado cuando se busca reforzar una decisión, valga por caso, cuando se quiere demostrar que el resultado del tratamiento tutelar ha sido exitoso en función de que el/la joven en cuestión "pudieron reencauzar su vida" "no volvieron a involucrarse en situaciones de riesgo", "adoptaron una actitud conforme a las normas", mostraron su voluntad de vivir pacíficamente en la sociedad", por lo tanto, hay que aplicar el beneficio absolutorio, "ya que aplicar una sanción no significaría más que excederse en una retribución negativa», o«resulta innecesario e ineficaz», o "en estas condiciones, aplicarle hoy una sanción sería actuar con un criterio meramente retributivo, desconociendo los logros alcanzados por el justiciable dentro de las posibilidades que le brinda el medio social en el que interactúa, puesto que, como han opinado las partes, su pronóstico favorable y su esfuerzo constituyen parámetros de que el tratamiento tutelar ha resultado eficaz".-

De mismo modo, cuando la conclusión lógica de las acciones emprendidas, amerita una sanción: "Ha demostrado total desinterés por conducirse correctamente, <por lo tanto $>$ además de haberse involucrado en una nueva causa ya como mayor, que se encuentra actualmente en pleno tramite, constituyendo una clara evidencia de la proclividad del "causante a colocarse en situaciones de riesgo. Además, luego se fuga del Comunidad Pucará, no concurrió más al tribunal, declarándose su rebeldía, a tal punto que se tuvo noticias de su actual paradero debido a un nuevo hecho delictivo que se le imputa como mayor, en el Juzgado Criminal y Correccional №2 de Zárate -Campana, permaneciendo detenido por largo tiempo. (Sentencia № 459/598 y 824/año 2002)

Este es un caso típico en que la encadenación es lineal, todo el tiempo se añaden agravantes, y esta serie de agravantes están encadenados con el "además": no bastaba con haberse involucrado en una condena como mayor, sino que además, se había fugado de una comunidad, mostrando reticencia al tratamiento iniciado, además, no concurrió más al tribunal, por lo tanto, se le declaró rebeldía, además la tal punto, recién se supo del imputado cuan- 
do se lo halló con otro hecho delictivo, por lo tanto, hay que proceder a aplicarle la sanción, ya que no es posible no reprochar la conducta del joven en cuestión. Con ese relato, es impensable no aplicar una sentencia condenatoria, el correlato de la condena suena lógico, y argumentado irrefutablemente.

Sin embargo, en el caso de las condenas, muchas veces la argumentación es presentada en la forma paradojal, es decir, estableciendo la concatenación argumental a través del uso del "Sin embargo": "Pese a las oportunidades brindadas, pese a la severa advertencia, no pudo, no aprovechó, no hizo, no cumplió, que en definitiva, al ser la consecuencia también negativa, restituye linealidad al asunto, porque en definitiva, no se hizo acreedor de la absolución, no se hizo acreedor de ninguno de los beneficios previstos en la ley minoril". La doble negación, es una afirmación, y por lo tanto, a aquellos que no hicieron ningún mérito, corresponde sancionarlos.

En esta argumentación genérica, hay una tonalización producto del uso de reforzadores y mitigadores (Vasilachis, 1992a y b, Pardo, 1992). En forma simple, se podría decir que los recursos reforzadores son aquellos que añaden carga semántica a un enunciado28, en tanto, los recursos mitigadores son los que le restan carga semántica.

Otra solución propugnada que se corresponde con el discurso argumentativo de la consecuencia lógica del éxito del resultado tutelar, tiene que ver con poner en foco las teorías del fin de la pena. Se suceden entonces los enunciados que sopesan las distintas penalidades, valorando especialmente una -la prevención especial- en detrimento de las otras que son resignadas en su utilidad.

$\mathrm{Al}$ respecto, son elocuentes las argumentaciones que suceden:

disponer una condena en esas condiciones únicamente serviría a los fines preventivos generales que, como hemos visto, quedan desplazados en el caso de los jóvenes comprendidos en la competencia específica de los jueces de menores", "disponer una condena en esas condiciones únicamente serviría a los fines preventivos generales,

La sola consideración de que, en el derecho penal juvenil no es legítima la concepción de la pena como prevención general, a diferencia del derecho penal común en el que todos concuerdan que ese fin es uno de los racionalmente previstos por la ley, permite aprehender claramente las diferencias entre uno y otro sistema normativo.
El fundamento jurídico de la pena juvenil es dual. Si bien la pena juvenil, al igual que el sistema de los medios correctivos, sirve siempre al castigo del hecho...en oposición al derecho penal de adultos, la necesidad de la expiación no debe deducirse siempre a partir del hecho cometido, de su gravedad y de la culpabilidad expresada en su comisión, sino también, e incluso primariamente, a partir de consideraciones pedagógicas, en las cuales el hecho, en cuanto tal, pasa a un segundo plano respecto de la prognosis a obtener a partir de la personalidad del autor.

Es claro que los magistrados refuerzan la función normalizadora en una pretensión educativa y no punitiva:

Todo medio de reacción adecuado al joven persigue primariamente tarea, o "al pretender ser la reacción jurídica dirigida al menor infractor una intervención de naturaleza educativas educativas...

En el relevamiento realizado, hubo de detectarse que solo uno de los tres camaristas, respaldaba su argumentos con textos jurídicos, en tanto los otros dos, solamente hacían alguna referencia bibliográfica o citaban jurisprudencia obligada en casos puntuales y por temas específicos (por ejemplo, la ausencia de pretensión fiscal como un elemento que marca el desistimiento de la acción pública; referencias al artículo 40 y $41^{\circ}$ del código penal con sus implicaciones, algún fallo en que confrontara jurisprudencia sobre "que es un arma". No era la modalidad de dos de los camaristas fundar su fallos con arreglo a posiciones trascendentes en la dogmática jurídica, ni nacional ni internacional. La llegada del tercer camarista pareció introducir algunos cambios, ya que éste empezó sistemáticamente a añadir contenido argumental a la sentencia, obligando, en casos de disidencia a contraargumentar.

Este movimiento se inició a mediados del año 2001, y con el paso de los años fue tomando una dinámica más interesante. Si bien, la mayor parte de la bibliografía y jurisprudencia citada corresponde a este camarista, lo que obviamente, sesga la mirada ideológica, no es menos cierto que el nivel de fundamentación de las sentencias fue incrementando su fuerza argumentativa y su complejidad a la par, configurando hacia el final del período un tablero de posiciones bastante estable. Así, en las segundas sentencias empezó a aparecer con cada vez mayor frecuencia, la Convención Internacional de los derechos del niño, y toda la legislación internacional de avanzada para personas menores de edad, vinculada a tratados internacionales, convenciones, y directrices adoptados por muchos países en el seno de las Naciones Unidas. 
Así, las ya famosas Reglas de Beijing, Reglas y Directrices de Ryad, la Opinión Consultiva 17, empezaron a dar vida a los fundamentos de las sentencias, amparadas en el "interés superior del niño". Hay interpretaciones que buscan la correcta hermenéutica de los artículos $3^{\circ}$ y $4^{\circ}$ de la ley 22.278 a la luz de la doctrina internacional.

La ausencia de fundamentación en las sentencias de menores podría explicarse por la suprema de que "para hacer el bien, no hay que rendir cuentas", y las mejores intenciones tutelares y la protección no requieren de justificaciones. Esta creencia está instalada, y el hecho de que muchos jueces se asuman a sí mismos como jueces de menores que aplican el derecho de menores y por ende, se sientan cobijados bajo el paraguas de la discrecionalidad buena (García Méndez, 1999), tiene como correlato que las sentencias no se fundamenten, porque el bien, la moral, el interés superior del niño son algo axiomáticamente deseable. En cambio los otros jueces, el grupo de los que se ven a sí mismos como jueces penales de menores que apuntan a la aplicación de un sistema de responsabilidad penal juvenil, tiene que fundamentar acerca de porque eligen aplicar la ley y no moral. Hasta tanto se modifique el régimen penal de la minoridad vigente, tienen que hace encomiables esfuerzos por buscar hermenéuticas que tornen adecuada la articulación de la ley con los estándares internacionales de justicia juvenil deseables. Mientras tanto esto no suceda, se valen de las mayores garantías, la más estricta observancia de los procedimientos con arreglo a provocar el menor daño, y apelan a la jurisprudencia que les confiera respaldo y legitimidad jurídica.*

\section{Notas}

1 Reza el párrafo final del artículo $1^{\circ}$ : "Si de los estudios realizados resultare que el menor se halla abandonado, falto de asistencia, en peligro material o moral, o presenta problemas de conducta, el juez dispondrá definitivamente del mismo por auto fundado, previa audiencia de los padres, tutor o guardador".

2 Una reconstrucción de distintos momentos legislativos, puede consultarse en Guemureman, Silvia: "Responsabilizar o punir. El debate legislativo en materia de niños, adolescentes y jóvenes infractores a la ley penal" (2004); Karen Jorolinsky y Denise Fridman: “QQué está sucediendo con los proyectos de responsabilidad penal juvenil? Un cambio que se aletarga en el Congreso de la Nación" (2007) y Proyectos de ley penal 2009 y 2012.

3 En Argentina, luego de la reforma judicial del año 1992, esta etapa del proceso se encuentra en manos de los Tribunales Orales de Menores, según lo estipula el artículo 2 del Código de procedimientos Competencia del tribunal de menores
Art. 28.- El tribunal de menores juzgará en única instancia en los delitos cometidos por menores que no hayan cumplido dieciocho (18) a los al tiempo de la comisión del hecho, aunque hubiese excedido dicha edad al tiempo del juzgamiento, y que estén reprimidos con pena privativa de la libertad mayor de tres (3) años .

El artículo 29 legisla la competencia de la primera instancia, los jueces de menores

Competencia del juez de menores

Art. 29.- El juez de menores conocerá:

1) En la investigación de los delitos de acción pública cometidos por menores que no hayan cumplido dieciocho (18) años al tiempo de la comisión del hecho.

2) En el juzgamiento en única instancia en los delitos y contravenciones cometidos por menores que no hayan cumplido dieciocho (18) años al tiempo de la comisión del hecho y que estén reprimidos con pena no privativa de la libertad o pena privativa de la libertad que no exceda de tres (3) años.

3) En los casos de simple inconducta, abandono material o peligro moral de menores que no hayan cumplido dieciocho (18) años al tiempo de encontrarse en esa situación, conforme lo establecen las leyes especiales.

4 Es usual que los jueces se refieran a las segundas sentencias como "los cuartos".

5 El expediente tutelar se abre en la primera instancia, en el juzgado de menores y acompaña al sujeto menor de edad a lo largo de la tramitación de su/s causa/s. Es frecuente que hechos distintos motiven la apertura de causas distintas y en no pocas ocasiones, la apertura de expedientes tutelares diferentes. No obstante, según la normativa que regula la competencia de los tribunales, debe ser uno solo el que prosiga las actuaciones. Es frecuente que los expedientes tutelares haya una intensa comunicación entre secretarios actuarios y tutelares de los distintos juzgados remitiéndose las respectivas actuaciones. La apertura de expedientes diferentes da lugar a la superposición de información una vez acumulados éstos, en los cuales debe corregirse la foliatura.

6 Cf. Jacques Derrida: "El siglo y el perdón". Entrevista con Wieciorka, en El siglo y el perdón seguida de fe y saber, 1era Edición en castellano, Ediciones de La Flor, 2003).

7 Cf. Viñas, Raúl Horacio: Delincuencia juvenil y Derecho penal de menores, Editorial Ediar, Buenos Aires, 1984.

8 Informes elevados por los Fiscales ante los TOM al Procurador General de la Nación. Informes anuales 2004, 2005, 2006 y sucesivos.

9 Dado que las actuaciones sobre personas menores de edad son "reservadas", hube de conformarme con 
el relevamiento de sentencias archivadas, de allí los años seleccionados. Avances sucesivos del procesamiento fueron presentados en distintos congresos, bajo la serie titulada Los jóvenes en las tenazas de la administración de justicia: Entre la fuerza de la ley y la fuerza del derecho. Se configuró progresivamente uno de los sustratos empíricos más fuertes de la tesis doctoral "La cartografía moral de las prácticas judiciales en los tribunales de menores" (Guemureman, 2008).

10 Dado que se trata de una segunda sentencia, el volcado de información es opcional, de modo que hay sentencias que contienen información sobre nacionalidad, fecha y lugar de nacimiento, condición de instrucción, y/o laboral, domicilio o lugar de residencia -instituto penal, unidad penitenciaria- y otras que no contienen ninguna información biográfica del imputado.

11 Estas son algunas de las fórmulas típicas utilizadas por los jueces cuando afirman que "no resulta procedente la aplicación del beneficio absolutorio previsto en el artículo 4⿳亠丷厂 o "que no se ha hecho acreedor de ninguno de los beneficios previstos".

12 En todos los casos se tomó el colectivo total de imputados, para el 2002, 144; para el 2003, 73; y para el 2004, 78.

$13 \mathrm{Al}$ respecto, Zaffaroni, R. , Alagia. A. Slokar, A: Manual de Derecho Penal, Parte General, Ediar, Buenos Aires, 2000. En el "Capítulo XXVI: Unidad y pluralidad de delitos", sostienen los autores que "conforme a los principios de un derecho penal de acto estricto, cuando un sujeto comete un delito solo puede aplicársele una pena, en tanto que si comete varios delitos habrá lugar para la imposición de varias penas (... ) cuando se parte del derecho penal de acto, se impone un tratamiento diferencial para el caso en que con una sola conducta se incurra en dos o más tipicidades (concurso ideal) y para el supuesto que para el mismo acto jurisdiccional deban juzgarse varias conductas típicas del mismo o de distinto tipo (concurso real o material)" (Pág. 815)

14 Todos los hurtos son agravados, sea por escalamiento o por haber dejado el vehículo en la vía pública. El carácter agravado explica que hayan llegado a la instancia de Tribunal Oral de Menores y no que hayan sido sustanciados íntegramente en la primera instancia.

15 La Cámara de Casación estableció que la segunda sentencia se debería dirimir en una audiencia en la cual se pase revista a la evolución del joven en cuestión. La ley 22.278, en cambio, no fija un procedimiento: "Lo que dice la ley es que para decir si condenás o no, tiene que haber estos requisitos, pero no dice ni dónde se hace, ni cómo se hace" (J11), responde uno de los jueces inquirido al respecto. Y esto lleva a que los distintos tribunales haciendo ecuaciones de posibilidad y tiempo, adopten modalidades diversas.

16 Al menos esta era la modalidad del TOM №1, en el cual se realizó el relevamiento objeto de esta base de datos. La modalidad del TOM №3, en cambio, era la de aplicar una formula típica al final, como coronación de todo un razonamiento que llevaba, ora a la absolución, ora a la condena. Ejemplos típicos fueron:

Absolución: Por todo ello, es que el Tribunal entiende adecuado y justo acceder a la exención de pena prevista en el art. $4^{\circ}$ de la Ley 22.278, dado que el menor demostró una buena readaptación, tanto social como laboral, no resultando entonces necesario ni eficaz aplicarle sanción alguna.-

Condena: En consecuencia, corresponde arribar a un pronunciamiento condenatorio en la presente causa, sin ninguno de los beneficios previstos por la Ley 22.278, en su artículo $4^{\circ}$,

O también, De la lectura del expediente tutelar $\mathrm{n}^{\mathbf{0}} 778$ del registro de este Tribunal y de estas actuaciones, surge que el encartado no ha demostrado un comportamiento que justifique la exención de pena prevista en el art. $4^{\circ}$ de la ley 22.278 .

17 Según Derrida (2003, ob. Cit. Págs. 7 a 39), "si digo: "Te perdono con la condición de que, al pedir perdón, hayas cambiado y no seas ya el mismo». ¿Acaso, te perdono? ¿Qué es lo que perdono?, ¿y a quien?, ¿perdono algo o a alguien?".

18 La porcentualización es sumamente necesaria para restituir la justa ponderación de cada año. Se compuso el cuadro sumando todos los imputados de las causas.

19 Los totales coinciden con el total de imputados presentes en las sentencias.

20 Millorini fue un caso paradigmático ya que mató al custodio de un importante político de nuestro país y recibió una sentencia ejemplar de prisión perpetua, que en la instancia de apelación, y acompañando el criterio de la Corte Suprema de Justicia, fue reducida a 15 años.

21 Esto pareciera demostrar la validez relativa de una de las máximas que orientar el accionar de los Tribunales de menores en su valoración de los resultados del expediente tutelar: la existencia de otras causas en forma posterior al reproche ínsito en la declaración de responsabilidad penal

22 Al respecto, consúltese Deleuze: "Baterbly o la Formula" (Pág. 63), en Preferiría no hacerlo, Ed. PRE-TEXTOS, Valencia, España, 2005.

23 Esta es la posición del Dr. Jantus, que ha expresado en algunas sentencias paradigmáticas que cuando no ha transcurrido mucho tiempo entre el momento de 
la comisión del nuevo delito y el cumplimiento de los 18 años, no corresponde valorar la ocurrencia de nuevos hechos como si fueran personas mayores de edad, y puede contemplarse aun las prerrogativas del artículo $4^{\circ}$.

24 En realidad sería más apropiado de hablar, tomando la sugerencia de Pardo (1992, Derecho y lingüística, p.34) hablar de "Voto del juez preopinante" y votos que adhieren o presentan divergencias. En las sentencias analizadas se dan casos que de disidencias típicas, es decir, en las cuales el voto del juez preopinante que funda una decisión, es rebatido en sus argumentos por el voto del juez que se expide en segundo lugar, y el tercero define, adhiriendo o al primero, o al segundo voto. También hay sentencias en que es el tercero el que presenta divergencias, y la mayoría queda compuesta por el voto de los dos primeros.

25 La Dra. Laura Pardo, en Derecho y lingüística (CEAL, 1992) realiza una análisis estrictamente jurídico de sentencias judiciales del fuero laboral. Su análisis de la estructura de la sentencia es útil para el análisis que se realiza aquí. Ella dice que cuando no hay disidencias, la resolución del tribunal, el FALLO, viene a re-rematizar el texto del juez preopinante, es decir, convalida el voto con sus argumentos. Aclara que "re-rematizar es re-actualizar el valor semántico del Rema del texto, con la misma intensidad (o mayor) con la que aparece la primera vez". En el caso de las disidencias, la anticipación remática que hace el juez preopinante, no coincide con el rema del texto de ficción del FALLO, y aquello que rerematiza es el voto de alguno de los otros jueces cuya disidencia adquirió fuerza argumentativa suficiente.(Pág.88 a 90)

26 Esta postura remite a la idea de perdón puro e incondicional, según Derrida, sería aquel que perdona lo imperdonable, sin cálculo alguno de beneficio ni expectativa de redención o transformación del sujeto a quien se perdona, es decir, "el perdón debe presentarse como lo imposible mismo". Derrida concluye ese tramo de su reflexión de este modo: "El perdón no es, no debería ser, ni normal ni normativo, ni normalizante. Debería permanecer excepcional y extraordinario, sometido a la prueba de lo imposible". (el resaltado, en el original).

27 Marion Carel en 1992 reformula la teoría de la argumentación en la lengua (TAL) concebida por DucrotAscombre en la década del '60, con la teoría de los bloques semánticos (TBS), superadora de la anterior. En ésta, el concepto de enunciado es superador del concepto de oración: un enunciado está por formado por el encadenamiento de dos segmentos de discurso unidos por un conector (CON). En la TBS el CON asume un valor normativo (si es Donc, "por lo tanto", en adelante PLT), o trasgresor (si es cependant, «sin embargo», en adelante, SE). SE y PLT son en el estadio actual del desarrollo de la teoría de TBS, las únicas formas posibles que puede tomar la conexión de dos segmentos de un encadenamiento argumentativo.

28 "La carga semántica es la cantidad de significado que posee un ítem lexical de por sí, más toda la información semántica que pueda/n aportarle/s él o los ítem lexicales que lo rodean y la que pueda darle el contexto" (Vasilachis, 1992:357)

\section{Referencias}

Beloff, Mary. "Algunas confusiones en torno a las consecuencias jurídicas de la conducta trasgresora de la ley penal en los nuevos sistemas de justicia latinoamericanos", en Revista Justicia y Derechos del Niño, N³, Buenos Aires, 2001.

DeleuzE, Gilles. “Baterby o la fórmula” En Preferiría no hacerlo, Ed. PRE-TEXTOS, Valencia, España, 2005.

Derrida, Jacques. "El siglo y el perdón". Entrevista con Wieciorka, en El siglo y el perdón seguida de fe y saber, 1era Edición en castellano, Ediciones de La Flor, 2003.

Ferrajoli, Luigi. “El derecho penal mínimo", publicado en Revista Doctrina Penal, Argentina,1986.

Garcia Mendez, Emilio Y Beloff, Mary (Comp.). Infancia, ley y democracia. Análisis crítico del panorama legislativo en el marco de la CIDN 1990-1998, Editorial TEMIS-Depalma, 1998.

García Méndez, Emilio. “Infancia, ley y democracia, una cuestión de justicia”, en García Méndez-Beloff, (comps.), Infancia, ley y democracia en América Latina, Editorial TEMIS, Bogotá, 2004.

Guemureman, Silvia Y Daroqui, Alcira. La niñez ajusticiada, Editores del Puerto, SIGLO XXI, Buenos Aires, 2001.

Guemureman, Silvia "Responsabilizar o punir. El debate legislativo en materia de niños, adolescentes y jóvenes infractores a la ley penal", en Revista Delito y Sociedad, Revista de Ciencias Sociales, №18-19, 2004. 
Guemureman, Silvia. La cartografía moral de las prácticas judiciales en los tribunales orales de menores de la Ciudad de Buenos Aires", Buenos Aires, Editores del Puerto, 2011.

Jorolinsky, Karen Y Fridman, Denise. “QQué está sucediendo con los proyectos de responsabilidad penal juvenil? Un cambio que se aletarga en el Congreso de la Nación", en el Sitio del Observatorio de Adolescentes y jóvenes (// observatoriojovenes.com.ar/category/procesos-legislativos/informes-observatorio-procesos-legislativos/page/2/ ). Informes 2007,2009 y 2012.

Llobet, Javier. "La sanción penal juvenil", en De la arbitrariedad a la justicia: Adolescentes y responsabilidad Penal en Costa Rica, (Gonzalez Oviedo, Mauricio Y Tiffer Sotomayor, Carlos coordinadores). Serie de Políticas, UNICEF- Regional y UNICEF -Costa Rica, 2000.

Martínez Vivot, Julio. El nuevo régimen penal de los menores, en La Ley Año XLV, №207, 1981.

Pardo, María Laura. Derecho y lingüística. Cómo se juzga con palabras. Análisis lingüístico de sentencias judiciales, Editorial CEAL, Buenos Aires, 1992.

Vasilachis De Gialdino, Irene. Enfermedades y Accidentes laborales. Un análisis sociológico y jurídico, Abeledo Perrot Editores, Buenos Aires, 1992.a.

Vasilachis De Gialdino, Irene. Métodos cualitativos I. Los problemas teórico-epistemológicos, Centro Editor de América Latina, 1992.

Vasilachis De Gialdino, Irene. El Análisis lingüístico en la recoleccion e interpretación de materiales cualitativos, en Métodos cualitativos II. La práctica de la investigación. Centro Editor de América Latina, 1992b.

Viñas, Horacio Raúl. Delincuencia juvenil y derecho penal de menores, EDIAR, Buenos Aires, 1984.

Zaffaroni, Eugenio Raúl - Alagia, Alejandro Y Slokar, Alejandro. Manual de Derecho Penal, Parte General, Ediar, Buenos Aires, 2000. 